\title{
Pulmonary Artery Pressure Profile in Atrial Septal Defect (ASD) Patients
}

\author{
Md. Serajul Haque ${ }^{1}, \mathrm{H}$ I Lutfur rahman Khan², Razia Sultana Mahmud ${ }^{3}$, Md. Faruq ${ }^{4}$, \\ Abdul Wadud Chowdury ${ }^{5}$, M Shomsher Ali ${ }^{6}$
}

\begin{abstract}
:
The objective of this study was to see the incidence of pulmonary hypertension and its age distribution in atrial septal defect (ASD) patients in our population. A total of 58 ASD (secundum type) patients were included in the study. The diagnosis was done with echocardiography. Subsequently patients under went cardiac
\end{abstract}

catheterization and their pulmonary artery (PA) mean pressure was measured. It was seen that pulmonary pressure increases with age. Severe PA hypertension (mean pressure $\geq \mathbf{4 0 ~} \mathrm{mm} \mathrm{Hg}$ ) was found in 14 patients (24.14\%), age range was $10-55$ years but most of them were more than 20 years old.

(Bangladesh Heart Journal 2015; 30(1) : 27-28)

\section{Introduction:}

Atrial septal defects usually go undetected in child hood. Patients usually present themselves in their middle age. ${ }^{1}$ Increasing disability in third and fourth decade of life are due to development of pulmonary hypertension and heart failure.

The frequency of pulmonary hypertension can be expected to increase with age. ${ }^{2}$ As many as $30 \%$ of adult patient with ASD have this finding. ${ }^{2}$ The majority of symptomatic adults beyond the age of 40 have mild to moderate pulmonary hypertension, that develops in presence of persistent large left to right shunt. ${ }^{3,4}$ Significant pulmonary hypertension seldom develop before third decade. 4,5,6 Many factors have been implicated as the cause of pulmonary hypertension, such as pulmonary emboli, progressive vascular changes, persistence of fetal type of pulmonary vessels and recurrent pulmonary infections. Mark ${ }^{7}$ reported that pulmonary artery pressure tend to be slightly higher in older patients. Eisenmenger's reaction occurs in less than $10 \%$ of patients with Atrial Septal

1. Associate Professor of Cardiology,Dhaka Medical College, Dhaka, E-mail: serajcardiology@yahoo.com

2. Professor of Cardiology, Anwer Khan Modern Medical College, Dhaka.

3. Rtd. Professor of Cardiology, National Institute of Cardiovascular Diseases, Dhaka

4. Rtd. Professor of Cardiology, National Institute of Cardiovascular Diseases, Dhaka

5. Professor of Cardiology, Dhaka Medical College (DMC), Dhaka.

6. Senior Consultant of Cardiology, Dhaka Medical College,Dhaka
Defect. $^{8}$ This study was done to see the pulmonary pressure profile of ASD patients in our population.

\section{Methods:}

This study was carried out in the Department of Cardiology, Dhaka Medical College Hospital, Dhaka during the period from January 2006 to December 2007. A total of 58 patients were selected from the in and out patient department of which 26 were male and 32 were female. Age range was 5-55 years. Those patients were selected who were clinically suspected as ASD and echocardiography demonstrated interatrial septal (IAS) defect in the region of fossa ovalies and colour doppler showed flow through IAS defect. Patients of ASD with pulmonary stenosis, cleft mitral valve,osteum primum ASD and Sinus venosus ASD were excluded from the study.

Cardiac catheterization was done and results determined according to the methods described by grossman. ${ }^{9}$ The pulmonary artery mean pressure was classified into normal, mild, moderate and severe when mean pressure (in $\mathrm{mm} \mathrm{Hg}$ ) was up to 20, 21-29, 30-39 and 40 or more respectively. ${ }^{10} \mathrm{All}$ the data were processed and analyzed manually.

\section{Result:}

Pulmonary artery pressure study was meticulously performed. The mean pulmonary artery pressure (PAP) was $31.90 \pm 20.93 \mathrm{~mm} \mathrm{Hg}$.(mean $\pm \mathrm{SD}$ ) with the range of 10-95 $\mathrm{mm} \mathrm{Hg}$. The mean PAP was $\leq 20 \mathrm{~mm} \mathrm{Hg}$ in 24 (41.38\%), between $21-29 \mathrm{~mm} \mathrm{Hg}$ in $13(22.41 \%)$, between $31-39$ 
$\mathrm{mm} \mathrm{Hg}$ in 7 (12.07\%) and $>40 \mathrm{~mm} \mathrm{Hg}$. in 14(24.14\%) cases (Table I). Total 34 patients showed elevated pulmonary pressure of which $12(35.19 \%)$ were $<20$ years of age and 22 (64.71\%) were above 20 (Table III). Among patients with severe pulmonary artery hypertension (mean pressure $>40 \mathrm{~mm} \mathrm{Hg}$.) there were 8 female and 6 male, age range was 10-55 years but most of them were more than 20 years old (Table III). In 24 patients PAmean pressure was normal $(<20 \mathrm{mmHg})$. Sixteen $(66.66 \%)$ of them were $<20$ years of age (Table IV).

Table-I

Pulmonary Artery (PA) Mean Pressure Distribution (n-58)

\begin{tabular}{lcccccc}
\hline Age Group & \multicolumn{3}{c}{ PA Pressure in mm Hg. } & \multicolumn{3}{c}{ Sex } \\
(Years) & $\leq 20$ & $21-29$ & $30-39$ & $\geq 40$ & Male & Female \\
\hline $0-10$ & 6 & - & 2 & 1 & 3 & 6 \\
$11-20$ & 10 & 5 & 2 & 2 & 8 & 11 \\
$21-30$ & 7 & 6 & 2 & 6 & 9 & 12 \\
$31-40$ & - & 2 & - & 4 & 4 & 2 \\
$>40$ & 1 & - & 1 & 1 & 2 & 1 \\
\hline Total & 24 & 13 & 7 & 14 & 26 & 32 \\
& $(41.38 \%)$ & $(22.41 \%)$ & $(12.07)$ & $(24.14 \%)$ & \\
\hline
\end{tabular}

Table-II

Distribution of raised PA mean pressure (n-34)

\begin{tabular}{|c|c|c|c|c|}
\hline Age Group & & ssure ir & & Total \\
\hline (Years) & 21-29 & $30-39$ & $\geq 40$ & \\
\hline Upto 20 & 5 & 4 & 3 & $12(35.19 \%)$ \\
\hline Above 20 & 8 & 3 & 11 & $22(64.71 \%)$ \\
\hline
\end{tabular}

Table-III

Distribution of Severe $(\geq 40 \mathrm{~mm} \mathrm{Hg}$.) PA Mean Pressure.

\begin{tabular}{lccc}
\hline Age in Years & Male & Female & Total \\
\hline Up to 20 & 2 & 1 & $3(21.43)$ \\
Above 20 & 4 & 7 & $11(78.57)$ \\
\hline
\end{tabular}

Table-IV

Distribution of Normal PA Pressure $(n=24)$

\begin{tabular}{lccc}
\hline Age in Years & Male & Female & Total \\
\hline Up to 20 & 6 & 10 & $16(66.67)$ \\
Above 20 & 3 & 5 & $8(33.33 \%$ \\
\hline
\end{tabular}

\section{Discussion:}

Cardiac catheterization showed mild to moderate pulmonary hypertension in $34.48 \%$ and severe pulmonary hypertension in $24.14 \%$ cases. It was seen that mean pulmonary pressure is mainly related with age and high pulmonary artery pressure is seen in the third decade and onward which correlates well with other previous studies. ${ }^{8,10}$ Besterman ${ }^{11}$ found pulmonary hypertension in $16 \%$ of his patients. Beller et al 12 commented that 30 to $50 \%$ of patients develop pulmonary hypertension sometime after the age of 20 years, Kelly and Lyons ${ }^{13}$ have reported pulmonary hypertension in 7 of 19 who were more than 45 years of age. So this study shows that patients of Atrial septal defect in our population develop pulmonary hypertension in third decade and onward like other populations. In this study sinus venosus and primum ASD are not included and sample size is small .Which are limitations of this study. So to make a firm comment a larger study with all types of ASD is needed.

\section{References:}

1. Schrier V, Vogelpoel: Atrial septal Defect; Am Heart J 1964;68:263-277.

2. Khoury $\mathrm{GH}$, and hawes $\mathrm{CR}$ : Atrial Septal Defect associated with pulmonary hypertension in children living at high altitudes. J Pediaatr 1967;70:432.

3. Gault JH, Morrow AG, Gray WA and Ross J. Atrial Septal defect in patients over the age of 40 years. Circulation 1968;37:26.

4. Saksena FBand Aldridge HE. Atrial septal defect in older patient.Circulation 1970; 42:1009.

5. Craig RJ and Selzer A. Natural history and prognosis of Atrial septal defect. Circulation 1968; 37: 805.

6. Evans JR, Rowe RD and Keith JD. The clinical diagnosis of Atrial septal defect in children. Am J Med 1961;30:345.

7. Mark H. Natural history of Atrial septal defect with criteria for selection for surgery. Am J Cardiol 1963; 12:66.

8. Perloff JK. Atrial septal defect in clinical recognition of congenital heart disease. $3^{\text {rd }}$ ed. Philadelphia: W B Saunders Co. 1987: 272-349.

9. Grossman $W$ and Baim DS. Cardiac Catheterization, Angiography and intervention. $4^{\text {th }}$ ed. Philadelphia: Lea and Febiger; 1991.

10. Dave SK, Pakrashi CB, Wooler HG, and Ionescu MI. Atrial septal defect in adults, clinical and haemodynamic result of surgery. AM J Cardiol; 1973; $31: 7$.

11. Besterman E. Atrial septal defect with pulmonary hypertension. Br Heart J 1961; 23:587.

12. Beller BM, Dexter L. Clinical and haemodynamic stability in patient with a large atrial septal defect . JAMA 1966; 195:180.

13. Kelly JJ Jr., Lyons HA. Atrial septal defect in aged. Ann Int Med 1958;48:67. 